\title{
Land Use and Land Cover Change (LULC) in the Lake Malawi Drainage Basin, 1982-2005
}

\author{
Geoffrey Chavula $^{1^{*}}$, Patrick Brezonik ${ }^{2}$, Marvin Bauer ${ }^{3}$ \\ ${ }^{1}$ University of Malawi-The Polytechnic, Blantyre, Malawi \\ ${ }^{2}$ Department of Civil Engineering, University of Minnesota, Minneapolis, USA \\ ${ }^{3}$ Department of Forest Resources, University of Minnesota, Saint Paul, USA \\ E-mail:gchavula@poly.ac.mw,brezonik@umn.edu,mbauer@umn.edu \\ Received March 16, 2011; revised April 18, 2011; accepted May 10, 2011
}

\begin{abstract}
Changes in land use and land cover (LULC) in the drainage basin of Lake Malawi over the period 1982 2005 were estimated from satellite imagery, and possible relationships were evaluated among the four major land-cover classes: cropland, forest, water, and savanna/shrub/woodland. AVHRR and MODIS sensors gave different values of areal extent of the four classes, limiting the feasibility of establishing consistent temporal trends over the entire period of the study, but forest land showed the least change among three land cover types, and extent of water bodies remained virtually unaltered over the period. AVHRR results show that cropland was mainly derived from savanna/shrub/woodland, which declined by almost $90 \%$ over the period 1982-1995.
\end{abstract}

Keywords: AVHRR, Lake Malawi, Lake Surface Temperature, MODIS, Reflectance

\section{Introduction}

Deforestation and agricultural production in the drainage basin of Lake Malawi have the potential to cause water quality deterioration that could impact the lake's rich biodiversity. Runoff from agricultural lands may increase loadings of suspended solids and nutrients to the lake, and rises in lake levels may be caused by reductions in interception and evapotranspiration when forests are converted to cropland. Forests intercept a large proportion of the rainfall, much of which is lost to the atmosphere through evapotranspiration. Forests transpire more water than crops, and these processes thus reduce surface runoff in forest environments.

According to Malawi's National Environmental Action Plan (NEAP) of 1994, rapid expansion of agricultural production from the mid-1970s to late 1980s resulted in extensive deforestation [1]. The rate of deforestation was $3.5 \%$ per annum during that period, but it declined to $1.6 \%$ by 1994 because little forested land was left. Additional deforestation was caused by use of wood fuel for tobacco curing, cooking, and domestic heating. Deforestation in the drainage basin of Lake Malawi may be similar to the national picture presented by the NEAP because the basin covers more than half of the country's total area. Detailed studies have not been reported on which land-cover class(es) contributed to the creation of cropland nor to confirm that depletion of forests led to increased cropland area.

The primary objectives of this study were to assess land-use and land-cover change (LULC) in the Lake Malawi drainage basin over the period 1982 - 2005 and to evaluate the source of new cropland. We used a combination of AVHRR and MODIS satellite imagery because the more sophisticated MODIS data were not available for much of the timeframe of interest. A secondary objective was to assess the comparability of LU$\mathrm{LC}$ results obtained from the two imagery sources.

\section{Lake Malawi Drainage Basin}

Lake Malawi is the third largest lake in Africa, and is located at the border between Malawi, Mozambique and Tanzania (Figure 1). Figure 1 shows the areal extent of the Lake Malawi Basin, depicted by the satellite imagery, with the lake's tributaries shown as solid lines and the boundary of the basin marked by dashed lines. The diamond dots represent ground observation points recorded during the field research aimed at verifying land use and land cover classes noted during the classification process. 


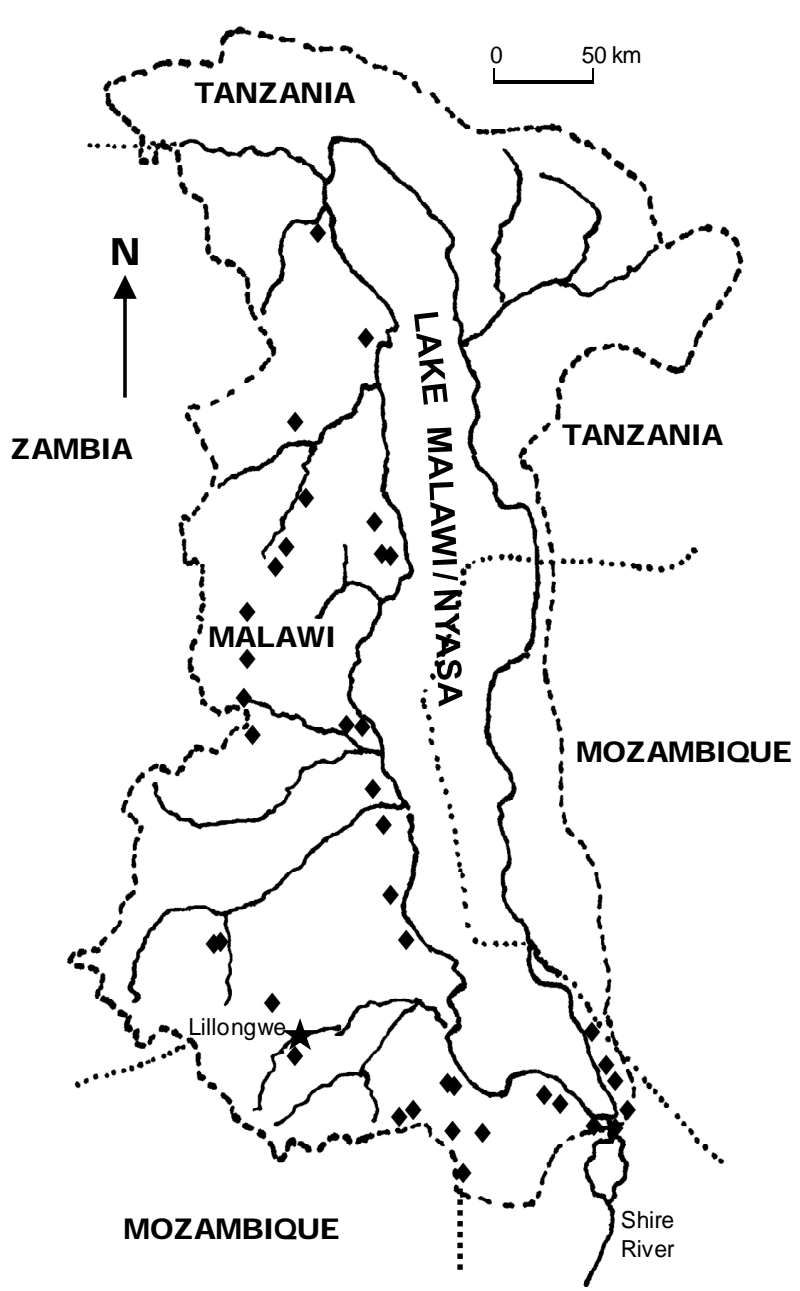

Figure 1. Map of Lake Malawi and its drainage basin with location of ground observation points shown as black diamonds.

These points appear as red dots on the satellite imagery.

The northern two-thirds of the Lake Malawi drainage basin are a mixture of evergreen (Braschystegia) woodlands and agriculture [2]. The southern third is woodland in Mozambique but almost completely cultivated in Malawi. The drainage basin has a higher population density $\left(100 \mathrm{~km}^{-2}\right)$ than that of Lake Tanganyika $\left(33 \mathrm{~km}^{-2}\right)$ but lower than that of Lake Victoria (up to $1200 \mathrm{~km}^{-2}$ ) [3]. The rapidly growing population in the Lake Malawi basin is sustained by small-scale agriculture, which causes increasing stress on the land, as increasingly marginal lands with steep slopes are brought into production $[3,4]$.

Water levels of Lake Malawi have varied widely over the period of continuous record [5]. The lake reached its lowest level, $469.94 \mathrm{~m}$ above mean sea level (MSL), in 1915, and outflow to the Shire River ceased until 1935. High lake levels occurred during 1979 - 1984, and a record rise $(1.83 \mathrm{~m})$ during 1978 - 1979 caused serious flooding of coastal areas and the Lower Shire Valley. Calder et al. [6] concluded from model simulations that rainfall variations alone were responsible for water level fluctuations from 1896 to 1967 but that a 13\% depletion of forest-cover in the basin during $1967-1990$ led to an increase in lake level. They concluded that if forest depletion not had occurred, the lake's water level would have been $1 \mathrm{~m}$ lower. In this respect, removal of forests from the basin saved the country from experiencing serious consequences from the 1991/92 drought.

During periods of heavy storms, rising lake levels trigger flooding in coastal areas and the Lower Shire Valley compounding the severity of flooding in the Zambezi River in Mozambique, downstream of the Shire River confluence [5,7]. The lake level also has implications for sustainability of hydropower plants in the Shire River, which generate $\sim 284 \mathrm{MW}$. They were developed after a flow-control structure was constructed in 1965 at Liwonde (the Kamuzu Barrage) to maintain the lake at 473.2 - $475.32 \mathrm{~m} \mathrm{MSL}$ and maintain a river flow of $\sim 170 \mathrm{~m}^{3} / \mathrm{s}$ [5]. Higher flows and levels could damage the structure.

\section{LULC Classification Using Satellite Imagery}

The procedure for determining changes in LULC using satellite imagery begins with selecting the phenomenon to represent change [8]. The following steps are then used to analyze the phenomenon: image acquisition, image preparation, selection of a change detection algorithm, and production of change detection results. Image preparation includes selecting images and eliminating interferences in them. Change detection involves either bi-temporal or trend analysis [8]. The former compares images from two discrete times, and the latter evaluates change based on data for multiple dates from a time series of images. Normally, anniversary dates are used for bi-temporal change detection to minimize effects of phenological cycles and sun angle.

Coppin et al. [9] grouped change-detection algorithms into eleven categories, and Coppin and Bauer [10] concluded that image differencing, PCA, and the multi-temporal Kauth-Thomas methods perform better than other approaches. As stressed by Jensen [11], the major assumption in change detection is that a difference exists in the spectral characteristics of a pixel on two dates if biophysical conditions in the pixel field changed between dates.

Vegetation indices often are used as empirical measures of vegetation status [12]. Many studies have demonstrated relationships between red and near-infrared (NIR) reflected energy and the amount and type of vege- 
tation on the ground [13]. According to Huete et al. [12], reflected red energy decreases with plant development because of absorption by chlorophyll in actively photosynthetic leaves, and reflected NIR energy increases through scattering processes in healthy leaves. A common vegetation index is the NDVI (normalized difference vegetation index):

$$
\mathrm{NDVI}=\frac{\left(X_{\text {nir }}-X_{\text {red }}\right)}{\left(X_{\text {nir }}+X_{\text {red }}\right)}
$$

The NDVI may range in value from -1.0 to +1.0 . A value of +1 indicates healthy vegetation; values close to zero indicate poor vegetation. Tropical forests show little intra-annual variation in NDVI, but rain-fed crops exhibit strong seasonality. Temporal signatures of NDVI vary according to vegetation type, and this is used to identify land-cover type (e.g., distinguish between forest and crop land).

\section{Methods}

The following datasets were used to conduct the analysis of LULC change: 8-km resolution AVHRR-NDVI data for $1982-2000$ and MODIS 7-Band Reflectance Data for 2000 - 2005, converted to NDVI (Table 1). In addition, we used Lake Malawi water level data from the Malawi Ministry of Irrigation and Water Development, Hydrology Section Data Archive, for the period 1982 2005 and ground observations for major land use and land-cover classes for the Lake Malawi basin, as well as Google Earth imagery, existing land use and land cover maps, and topographic maps.

LULC analysis was done using the method of Thenkabail et al., which involves class development byspec- tral matching techniques (SMTs), followed by class identification and merging using ground observations, Google Earth imagery, and other secondary data to produce maps of LULC classes for each year of data $[14,15]$. Areal coverage by LULC class was used to measure changes over the period 1982-2005. Two SMT variations were used to classify LULC change- spectral correlation similarity (SCS) and spectral similarity value (SSV). Thenkabail et al. [16] showed that both are useful in classifying LULC types.

SCS is based on Pearson's correlation coefficient $(r)$ applied to an NDVI time series [14]:

$$
r=\frac{1}{n-1}\left[\frac{\sum_{i=1}^{n}\left(t_{i}-\mu_{t}\right)\left(h_{i}-\mu_{h}\right)}{\sigma_{t} \sigma_{h}}\right]
$$

where $t_{i}=$ NDVI time series of the target class; $\mu_{t}=$ mean of the NDVI time series of the target class; $h_{i}=$ NDVI time series of any other class; $\mu_{h}=$ mean of the NDVI time series of any class; $\sigma_{t}=$ standard deviation of target class NDVI time series; and $\sigma_{h}=$ standard deviation of NDVI time series of other class. Although $r$ can range from -1.0 to +1.0 , negative values are not meaningful here [14]. The higher the value of $r$, the greater the similarity of the spectral or temporal NDVI profile between the historical and recent time series land-use and land-cover class [15].

SSV was defined by Homayouni and Roux [16] as:

$$
\mathrm{SSV}=\sqrt{\mathrm{EDS}^{2}+(1-r)^{2}}
$$

where EDS is the Euclidian distance between the histori-

\begin{tabular}{|c|c|c|c|}
\hline Satellite Sensor and Band & Wavelength $(\mu \mathrm{m})$ & Data Format & Range \\
\hline \multicolumn{4}{|l|}{$\underline{\operatorname{AVHHR}(8 \mathrm{~km})}$} \\
\hline Band 1 (B1) & $0.58-0.68$ & Reflectance at ground, 8-bit & $0-100 \%$ \\
\hline Band 2 (B2) & $0.73-1.10$ & Reflectance at ground, 8-bit & $0-100 \%$ \\
\hline Band 4 (B4) & $10.3-11.3$ & $\begin{array}{l}\text { Brightness temperature } \\
\text { (top of atmosphere) }\end{array}$ & $160-340$ \\
\hline Band 5 (B5) & $11.5-12.5$ & $\begin{array}{l}\text { Brightness temperature } \\
\text { (top of atmosphere) }\end{array}$ & $160-340$ \\
\hline NDVI & $(\mathrm{B} 2-\mathrm{B} 1) /(\mathrm{B} 2+\mathrm{B} 1)$ & No units, 8-bit scaled NDVI & -1 to +1 \\
\hline \multicolumn{4}{|l|}{ MODIS/Terra } \\
\hline $\begin{array}{l}\text { 7-Band-500 m reflectance data } \\
\text { processed to NDVI }\end{array}$ & $(\mathrm{B} 2-\mathrm{B} 1) /(\mathrm{B} 2+\mathrm{B} 1)$ & No units; 16-bit scaled NDVI & -1 to +1 \\
\hline
\end{tabular}
cal LULC class and a recent LULC class in spectral

Table 1. Datasets used for LULC change in Lake Malawi drainage basin. 
space [15]. SSV was used to match both the shape and magnitude of the classes. The Euclidian distance EDS is given by:

$$
\mathrm{EDS}=\sqrt{\sum_{i=1}^{n}\left(t_{i}-r_{i}\right)^{2}}
$$

The typical range of SSV is 0 - 1.415; smaller values indicate greater similarity.

Monthly data on the maximum-value composite NDVI for AVHRR were downloaded for the Lake Malawi basin from the International Water Management Institute Data Support Pathway (IWMI DSP) archive for 1982 1995; and maximum composite NDVI values for MODIS/Terra were calculated for the Lake Malawi basin from 7-Band Reflectance Data of bands 1 and 2 for 2000 - 2005 using ERDAS Imagine and ER Mapper computer packages. The cloud removal algorithm of Thenkabail et al. [14] was not used because we assumed that the composite NDVI values eliminated cloud interference by making use of at least one cloud-free day in computing the data series.

Unsupervised land cover classification was carried out on the NDVI series by the ISODATA routine in ERDAS Imagine, which calculates class means evenly distributed in the data space and clusters the remaining pixels iteratively using a minimum distance technique. Initially, 50 classes were defined, from which NDVI was plotted versus month for the period 1982 - 2000. Spectral matching by SCS then was used to group signatures representing similar classes. The process started by grouping classes with $r^{2} \geq 0.96$, followed by $0.92 \leq r^{2}<0.96$, $0.90 \leq r^{2}<0.92,0.85 \leq r^{2}<0.90$, and finally $r^{2}<0.85$. The choice of $\mathrm{r}^{2}$ ranges was made based on previous experience with LULC classification. In each range, signatures were classified further into smaller groups depending on similarity of the NDVI signatures. After merging, further grouping was done with the assistance of ground observation photos, Google Earth, the USGS land-use/land- cover map, Global Land Cover (GLC) 2000 land-use/ land-cover map, and the Malawi Department of Surveys draft LULC map. A single class was assigned to each $8 \mathrm{~km} \times 8 \mathrm{~km}$ pixel in AVHRR images and each $0.5 \mathrm{~km} \times 0.5 \mathrm{~km}$ pixel in MODIS images after examining the accessory information. Finally, four classes were obtained: water bodies, cropland, evergreen forests, and savanna/ shrubs/woodland (SSW).

For both AVHRR and MODIS images, verification of the identified classes was done using geo-linked landuse/land-cover maps (USGS, GLC), Landsat and Google Earth imagery, and ground observation photos. Pixels falling in the "wrong" category were cropped out of the image and placed in the appropriate class. For example, several pixels falling in the cropland, SSW, or forest categories found in Lake Malawi in the analyses of MODIS images were cropped out and placed under "water bodies."

Ground observations were made for the LULC classes at specific locations in the Lake Malawi basin, shown in Figure 1 as diamond dots and red dots on the satellite imagery. A Garmin GPS unit was used to locate the ground observation points. Collection of ground-based calibration data for the LULC classification focused on dominant classes, namely: evergreen forests; patches of natural woodlands (including Miombo); grassland; shrub and scrub land; "dambos" (i.e., wetlands in the plateau area); and farmland, including home gardens. Collection of calibration data involved travel to basin areas where these classes were thought to occur. This approach differs from the common approach to collect ground observation data-sampling on a uniform length scale (e.g., every $10 \mathrm{~km}$ of road travel), which would not have been useful because most of the land in the basin falls in the cropland class.

\section{Results and Discussion}

A wide variety of patterns occurred in monthly values of NDVI calculated from 2001 MODIS data among the 50-unsupervised LULC classes extracted by ERDAS ISODATA. The variations of NDVI of the 50 classes with time in months are shown in Figure 2(a); but many classes of LULC did exhibit substantial similarity. For example, classes 17, 19, and 26 shown in Figure 2(b) were merged into one group because their correlation coefficient was greater than 0.96, i.e., SCS of $r^{2}>0.96$. Figures 2(a) and 2(b) illustrate transitional results obtained in the classification process before the four final LULC classes were identified, namely: water bodies, cropland, evergreen forests, and savanna/shrubs/woodland (SSW).

Spatial distributions of the final four LULC classes over the study period are shown in Figure $3(8-\mathrm{km}$ resolution AVHRR-NDVI data for 1982, 1985, 1990, and $1995)$ and Figure 4 (0.5 km resolution MODIS-NDVI data for 2001 and 2005). Inspection of the areal extent data for each LULC class over the six years (Table 2) shows that the two sensors yielded discordant results regarding areal extents of the classes and changes in LULC in the Lake Malawi basin over the period of analysis. Consequently, it is more instructive to consider the two image sources separately.

For AVHRR, forest area decreased by $\sim 25 \%$ initially (1980 to 1985) and then increased gradually during the period 1985 - 1995 such that the extent of forest in 1995 was within $91 \%$ of the initial value. The area of cropland nearly doubled between 1982 and 1985 but then re- 


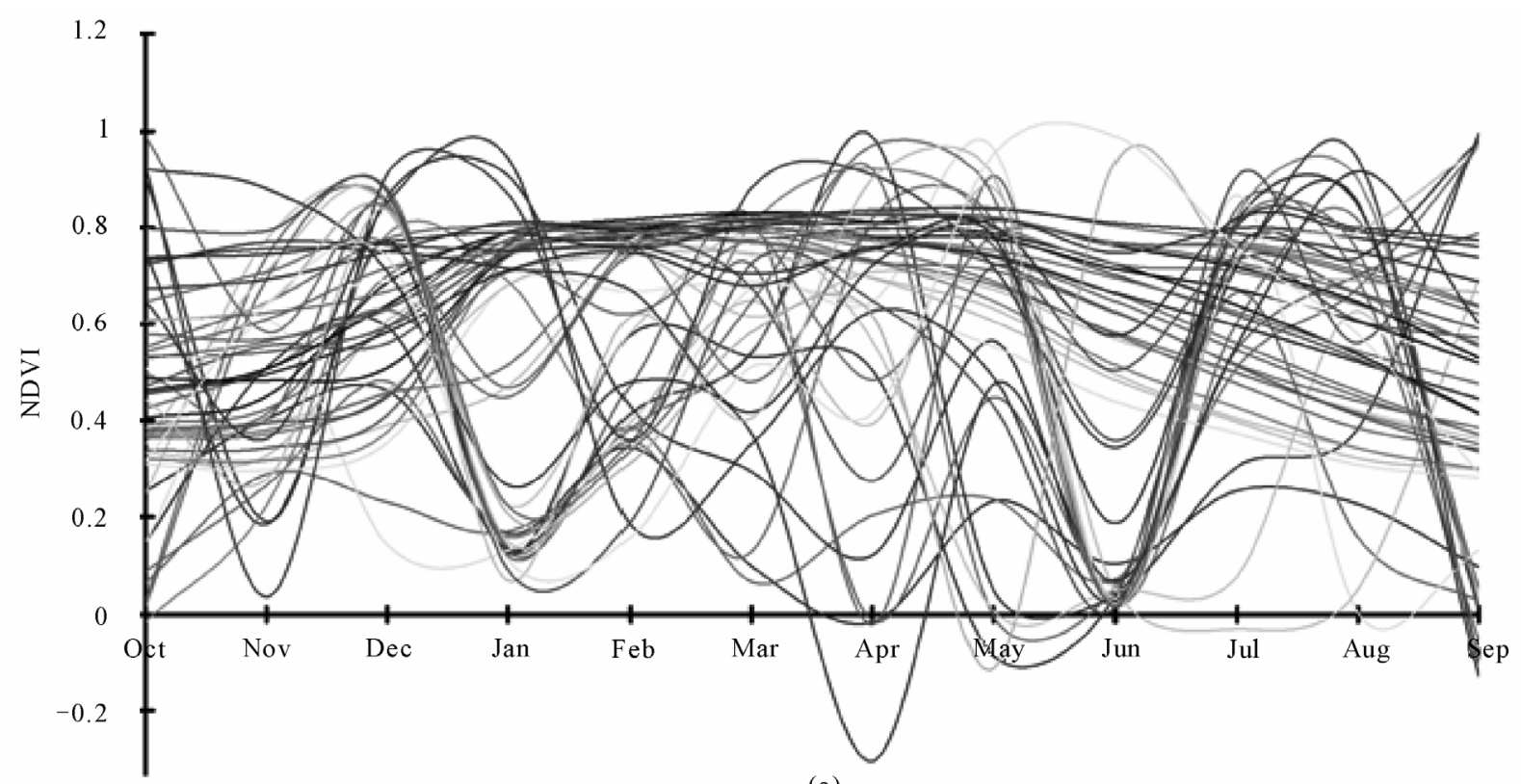

(a)

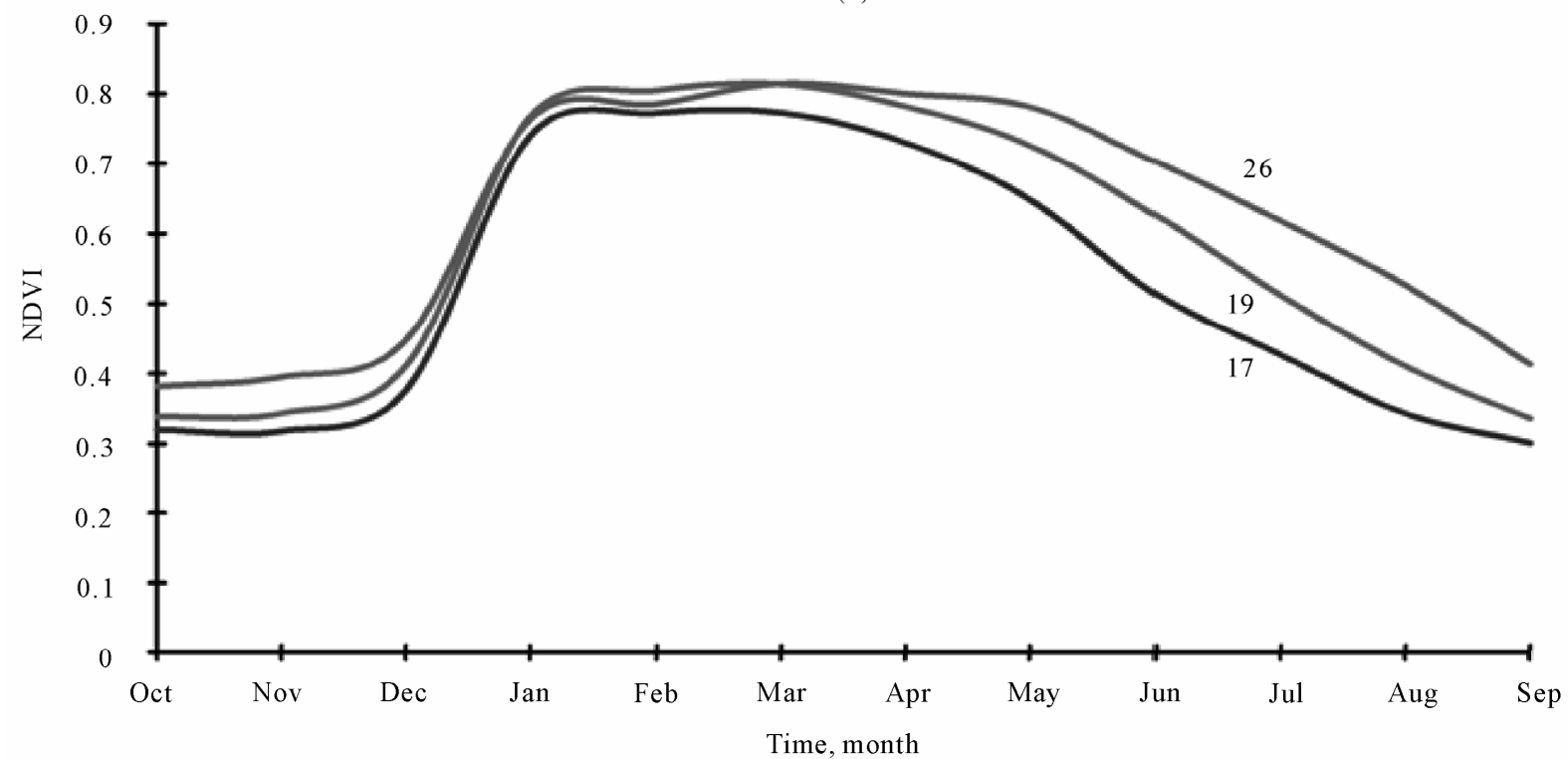

(b)

Figure 2. (a) NDVI versus month for 50 classes produced by unsupervised classification for 2001 MODIS data; (b) plots for three of the classes with SCS $R^{2}>0.96$.

mained relatively constant. In contrast, the area of savanna/shrub/woodland (SSW) decreased dramatically, especially between 1982 and 1985, and by 1990 the extent of SSW was only $13 \%$ of the 1982 value. The results indicate that cropland area increased primarily at the expense of SSW. The area of surface water remained fairly constant over the period of AVHRR data, although it increased by $\sim 9 \%$ between 1990 and 1995. For MODIS, forested and water areas were fairly constant between the two years of data, but cropland decreased and SSW increased by similar amounts. Thus cropland and SSW again appear to be interchangeable.

Analysis of LULC data from the two sensors yielded moderate differences in areal extent for forested land, with the MODIS imagery yielding about a third more forest than the AVHRR imagery. The two sensors yielded even larger differences in extent for cropland and SSW, but they did agree on the areal extent of surface water, which essentially represents Lake Malawi. The differences in areal coverage for the three land classes likely can be attributed to differences in spatial resolution of the sensors. Much more class-averaging occurs 


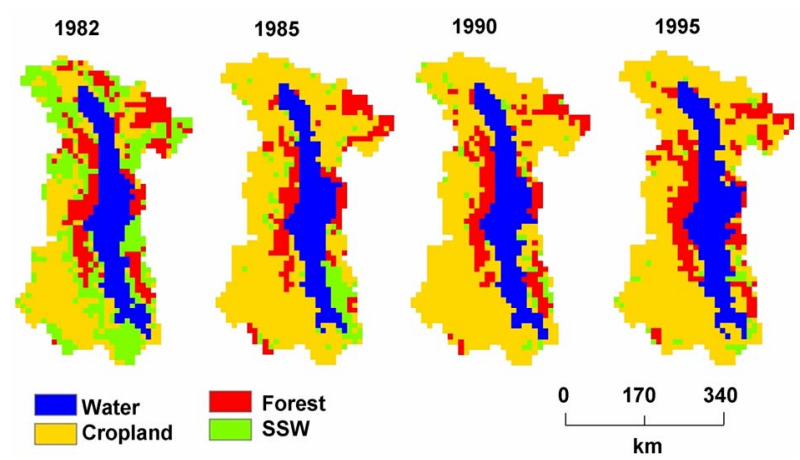

Figure 3. Distribution of the four LULC classes in Lake Malawi basin from AVHRR imagery for (a) 1982, (b) 1985, (c) 1990, and (d) 1995.

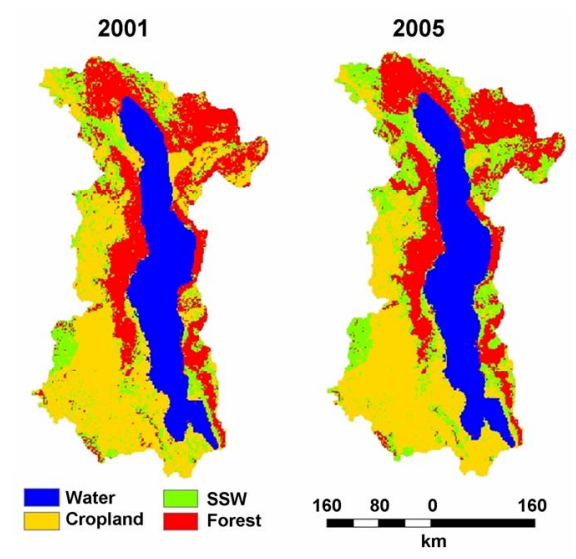

Figure 4. Distribution of the four LULC classes in Lake Malawi basin from MODIS imagery for (a) 2001 and (b) 2005.

with the AVHRR data, given its low $(8 \mathrm{~km})$ resolution, than with the MODIS data. Hence, small differences between classes are more likely to be distinguishable using MODIS than AVHRR data. Because surface water in the basin occurs mostly in one large water body, averaging of within-pixel spectral characteristics is much less an issue for this class than for spatially heterogeneous land classes.
The temporal changes in LULC areal coverage (Table 2) show no obvious relationship between forest depletion and lake level rise. From the AVHRR data, it appears that there was a small net decrease in forests between 1982 and $1995(<9 \%)$, but the lake level decreased by $2.4 \mathrm{~m}$. The MODIS data show a small $(3 \%)$ decease in the extent of forests from 2001 to 2005 , but the lake level rose by $0.3 \mathrm{~m}$. The differences in areal coverage of forest between the two sensors preclude combining the data to examine relationships between water level and forest over the entire study period.

The results in Table 2 indicate that SSW lands rather than forests have suffered the most serious depletion in the Lake Malawi basin as cropland has expanded and agricultural production has increased. These findings contrast the results of Calder et al. [6], who concluded that forest depletion in the basin of Lake Malawi caused an increase in lake level. Although evapotranspiration may not be as high in SSW as in forests, because rainfall interception by broad leaves of the evergreen forests is generally high and thus associated evaporation losses are also high and accentuated by eddies generated by wind blowing over the forest stand, the increase in surface runoff that likely results from converting SSW to cropland nonetheless has the potential to increase the lake level.

Most of the Lake Malawi Basin is covered by SSW hence it is not surprising that cropland is mainly from this LULC class. The other reason for this scenario is that areas where forests occur in the Lake Malawi Basin are sparsely populated. Thus, there is very little effect on forest cover with the encroachment of human activities such as agricultural production. But this situation is being to change in future as more people in Malawi move into forest areas in search of prime land for settlement and agricultural production, especially tobacco and maize production.

The differences between the AVHRR and MODIS data for areal extent of the LULC classes were unexpected, but upon reflection the differences do make sense

Table 2. Areal extent of LULC classes (in $\mathrm{km}^{2}$ ), and lake level (m above sea level) in Lake Malawi drainage basin.

\begin{tabular}{ccccccc}
\hline Year & Imagery & Forest & Cropland & Water Bodies & SSW $^{\mathbf{1}}$ & Lake Level \\
\hline 1982 & AVHRR & 26741 & 45738 & 29040 & 43681 & 476.05 \\
1985 & AVHRR & 20086 & 86273 & 28193 & 10648 & 475.17 \\
1990 & AVHRR & 22264 & 87846 & 29403 & 5687 & 475.42 \\
1995 & AVHRR & 24442 & 83490 & 31944 & 5324 & 473.66 \\
2001 & MODIS & 33800 & 46408 & 29707 & 20091 & 474.51 \\
2005 & MODIS & 32739 & 40545 & 29799 & 26921 & 474.83 \\
\hline
\end{tabular}

${ }^{1} \mathrm{SSW}=$ savanna/shrub/woodlands. 
given the large difference in spatial resolution between the two sensors and the patchy nature of land cover in Malawi. Because of the short temporal extent (2001 2005) of MODIS data, our analysis of temporal trends is based primarily on the AVHRR data. If we had been able to use 1-km AVHRR-NDVI data instead of 8-km resolution data, the inferred LULC distributions may have been more compatible with the MODIS results, but such data were not available.

\section{Conclusions}

Because of differences in spatial resolutions, AVHRR and MODIS sensors gave different values for areal extent of the forest, cropland and SSW land classes over the period of analysis. The extent of surface water remained virtually unchanged over the period 1982 - 2005. Both the AVHRR and the MODIS data show that cropland was mainly derived from SSW.

\section{Acknowledgements}

The authors thank the International Water Management Institute (IWMI), University of Minnesota, and START for funding for the study. Use of the facilities of the Remote Sensing Laboratory and Water Resources Center at the University of Minnesota and Monkey Bay Fisheries Research Station in Malawi is greatly appreciated. We are happy to acknowledge technical support from James Kuyper, NASA; John Sapper, NOAA; Ye Myint, Leica; Prasad Thenkabail, USGS; and the Ministry of Irrigation and Water Development in Malawi.

\section{References}

[1] Environmental Affairs Department, "National Environmental Action Plan," Malawi Government, Lilongwe, 1994.

[2] H. A. Boostma and R. E. Hecky, "Conservation of the African Great Lakes: A Limnological Perspective," Conservation Biology, Vol. 7, No. 3, 1993, pp. 644-656. doi:10.1046/j.1523-1739.1993.07030644.x

[3] H. Bootsma and S.E. Jorgensen, "Lake Malawi/Nyasa," 2004.

http://www.worldlakes.org/uploads/ELLB\%20Malawi-N yasaDraftFinal.14Nov2004.pdf

[4] F. X. Mkanda, "Contribution by Farmer's Survival Strategies to Soil Erosion Strategies in the Linthipe River Catchment: Implications for Biodiversity Conservation in Lake Malawi/Nyasa," Biodiversity and Conservation, Vol. 11, No. 8, 2002, pp. 1327-1359. doi:10.1023/A:1016265715267
[5] O. N. Shela, "Naturalization of Lake Malawi Levels and Shire River Flows: Challenges of Water Resources Research and Sustainable Utilization on the Lake Malawi Shire River System," Water Net Symposium: Sustainable Use of Water Resources, Maputo, 1-2 November 2000, pp. 1-12.

[6] I. R. Calder, R. L. Hall, H. G. Bastable, H. M. Gunston, O. Shela, A. Chirwa and R. Kafundu, "The Impact of Land Use Change on Water Resources in the Sub-Saharan Africa: A Modeling Study of Lake Malawi," Journal of Hydrology, Vol. 170, No. 1-4, 1995, pp. 123-135. doi:10.1016/0022-1694(94)02679-6

[7] S. S. Chiotha, G. M. S. Chavula, S. Chikwembani, E. B. Khonga and E. Y. Sambo, "National Disaster Management Plans for Malawi," Ministry of Disaster, Relief and Rehabilitation, Lilongwe, 1997.

[8] J. Sakulich, "Procedures and Considerations for Conducting Digital Change Detection," 2002. http://www.personal.psu.edu/users/j/b/jbs191/steps.htm

[9] P. Coppin, I. Jonckheere, K. Nakaerts, B. Muys and E. Lambin, "Digital Change Detection Methods in Ecosystem Monitoring: A Review," International Journal of Remote Sensing, Vol. 25, 2004, pp. 1565-1596. doi: $10.1080 / 0143116031000101675$

[10] P. L. Coppin and M. Bauer, "Change Detection in Forest Ecosystems with Remote Sensing Digital Imagery," Remote Sensing Reviews, Vol. 13, No. 3-4, 1996, pp. $207-$ 234.

[11] J. R. Jensen, "Introductory Digital Image Processing: A Remote Sensing Perspective," Prentice-Hall, Upper Saddle River, 1996.

[12] A. Huete, C. Justice and W. Leeuwen, "MODIS Vegetation Index (MOD 13). Algorithm Theoretical Basis Document Version 3," NASA-Goddard Space Flight Center, Greenbelt, 1999.

[13] J. E. Colwell, "Vegetation Canopy Reflectance,"' Remote Sensing of Environment, Vol. 3, No. 3, 1974, pp. 175183. doi:10.1016/0034-4257(74)90003-0

[14] P. S. Thenkabail, M. Schull and H. Turral, "Ganges and Indus River Basin Land Use/Land Cover (LULC) and Irrigated Area Mapping Using Continuous Streams of MODIS Data," Remote Sensing of Environment, Vol. 95, No. 3, 2005, pp. 317-341. doi:10.1016/j.rse.2004.12.018

[15] P. S. Thenkabail, G. Parthasaradhi, T. W. Biggs, M. K. Gumma and H. Turral, "Spectral Matching Techniques to Determine Historical Land Use/Land Cover (LULC) and Irrigated Areas Using Time-Series AVHRR Pathfinder Datasets in the Khrishna River Basin, India," Photogrammetry and Remote Sensing, Vol. 73, No. 9, 2007, pp. 1029-1040.

[16] S. Homayouni and M. Roux, "Hyperspectral Image Analysis for Material Mapping Using Spectral Matching in an Urban Area," Computer and Information Science, Vol. 35, No. 7, 2004, pp. 49-54. 